\title{
The Challenge of Distinguishing POEMS from Chronic Inflammatory Demyelinating Polyneuropathy-Importance of Early Recognition and Diagnosis of POEMS
}

\author{
Frances Chow, ${ }^{1}$ Leila Darki ${ }^{2}$ and Said R Beydoun ${ }^{2}$
}

1. Department of Neurology, Keck School of Medicine, University of Southern California, Los Angeles, CA, US,

2. Neuromuscular Division, Department of Neurology, Keck School of Medicine, University of Southern California, Los Angeles, CA, US

$\mathrm{P}$ OEMS is a rare syndrome characterized by the unique constellation of polyneuropathy, organomegaly, endocrinopathy, M-proteins, and skin changes. Correct diagnosis is often delayed in early stages of the syndrome when patients exhibit only isolated polyneuropathy due to the clinical and electrodiagnostic similarities with chronic inflammatory demyelinating polyneuropathy. We describe a case in which early suspicion for POEMS uncovered underlying malignancy, and we review the clinical, electrophysiological, pathological, and laboratory findings characteristic of POEMS. The importance of high clinical suspicion is key in the proper diagnosis and management of this complex syndrome.

\section{Keywords}

POEMS syndrome, chronic inflammatory demyelinating polyneuropathy (CIDP), demyelinating neuropathy, vascular endothelial growth factor (VEGF), monoclonal gammopathy

Disclosures: Frances Chow, Leila Darki and Said R Beydoun have no relevant conflicts to declare.

Review Process: Double-blind peer review.

Compliance with Ethics: Procedures were followed in accordance with the responsible committee on human experimentation and with the Helsinki Declaration of 1975 and subsequent revisions. Informed consent was received from the patient for publication of this case report.

Authorship: All named authors meet the International Committee of Medical Journal Editors (ICMJE) criteria for authorship of this manuscript, take responsibility for the integrity of the work as a whole, and have given final approval to the version to be published.

open Access: This article is published under the creative commons Attribution Noncommercial License, which permits any noncommercial use, distribution, adaptation, and reproduction provided the original authors and source are given appropriate credit. (c) The Authors 2018.

Received: March 18, 2018

Accepted: May 14, 2018

Citation: US Neurology. 2018;14(2):94-7

Corresponding Author: Frances Chow, Department of Neurology, Keck School of Medicine, University of Southern California, 1520 San Pablo St, Suite 3000, Los Angeles, CA 90033, US. E: Frances.Chow@med.usc.edu

Support: No funding was received in the publication of this article.
POEMS syndrome is a rare paraneoplastic syndrome characterized by a complex constellation of systemic findings in the setting of a proliferative cell disorder. Named for peripheral neuropathy, organomegaly, endocrinopathy, $\mathbf{M}$-proteins, and skin changes, these findings are predominant among several other associated features of the syndrome.

We describe a case in which the diagnosis of POEMS was suspected in the setting of neuropathy with skin changes, and was confirmed by subsequent hematological evaluation. Special emphasis in this case report is placed on the neurological clinical suspicion and workup in identifying a life-threatening condition, particularly the clinical and diagnostic challenge of distinguishing POEMS from chronic inflammatory demyelinating polyneuropathy (CIDP). Our experience with this patient reinforces the importance of early recognition and diagnosis of POEMS.

\section{Case report}

A 44-year-old previously healthy male presented to his primary care provider with 2 weeks of dull bilateral foot pain localized at the great toes and aggravated by movement. He denied any injury to the toe or erythema of the joint. Examination at that time was notable for absent sensation to light touch and monofilament over the distal parts of the feet. Radiographic imaging demonstrated mild bilateral hallux valgus deformities with small bunions, without any fracture, dislocation, or suspicious osseous lesion. At a subsequent visit, 3 months after the onset of symptoms, an electrodiagnostic study was requested. It revealed a sensory-motor neuropathy with length-dependent characteristics (Table 1 , Table 2). Pathophysiology was consistent with a demyelinating process with secondary axonal loss Diagnosis of CIDP was considered by the electromyographer.

The patient was subsequently lost to follow-up and presented 8 months later at the Neurology Clinic with progressive weakness and worsening distal sensory dysesthesias. Basic neuropathy workup for treatable causes was unremarkable. Cerebrospinal fluid (CSF) showed albuminocytologic dissociation with a protein of $98 \mathrm{mg} / \mathrm{dL}$

The patient was then referred to our Neuromuscular Clinic with a clinical diagnosis of CIDP and recommendation for intravenous immunoglobulin therapy (IVIG). Additional history obtained indicated an unintentional weight loss of 50 pounds over 8 months and intermittent headache with blurry vision over 3 months. Motor examination (based on the Medical Research Council Motor Examination scale 
Table 1: Motor nerve conduction studies

\begin{tabular}{|l|l|l|l|}
\hline Nerve and site & Latency (ms) & Amplitude (mV) & Conduction velocity \\
\hline Tibial R & $\mathrm{N}<5.8$ & $\mathrm{~N}>4$ & $\mathrm{~N}>40$ \\
\hline Ankle & 12.5 & 0.1 & \\
\hline Popliteal fossa & 32.2 & 0.1 & 16.7 \\
\hline Tibial L & $\mathrm{N}<5.8$ & $\mathrm{~N}>4$ & $\mathrm{~N}>40$ \\
\hline Ankle & 13.6 & 0.2 & \\
\hline Popliteal fossa & 39.3 & 0.1 & 14.2 \\
\hline Peroneal L & $\mathrm{N}<6.4$ & $\mathrm{~N}>2.2$ & $\mathrm{~N}>40$ \\
\hline Ankle & 12.6 & 0.2 & \\
\hline Fibula (head) & 26.4 & 0.2 & 21.7 \\
\hline Popliteal fossa & 29.5 & 0.2 & 35.4 \\
\hline Peroneal R & $\mathrm{N}<6.4$ & $\mathrm{~N}>2.2$ & $\mathrm{~N}>40$ \\
\hline Ankle & 13.9 & 0.2 & \\
\hline Fibula (head) & 31.3 & 0.1 & 15.1 \\
\hline Popliteal fossa & 35.4 & 0.1 & 29.2 \\
\hline Median L & $\mathrm{N}<4.4$ & $\mathrm{~N}>5$ & $\mathrm{~N}>49$ \\
\hline Wrist & 4.6 & 6.4 & \\
\hline Elbow & 12.1 & 7.0 & 28.0 \\
\hline Ulnar L & $\mathrm{N}<4.4$ & $\mathrm{~N}>5$ & $\mathrm{~N}>49$ \\
\hline Wrist & 5.2 & 8.5 & \\
\hline Below elbow & 12.6 & 5.7 & 4.3 \\
\hline Above elbow & 16.1 & & \\
\hline & & & \\
\hline & & & \\
\hline
\end{tabular}

$R=$ right $\mathbf{L}=$ left; $m s=$ millisecond $m \mathrm{mV}=$ millivolt; $N=$ normal.

Table 2: Sensory nerve conduction studies

\begin{tabular}{|l|l|l|l|l|}
\hline Nerve and site & $\begin{array}{l}\text { Onset } \\
\text { latency }(\mathrm{ms})\end{array}$ & $\begin{array}{l}\text { Peak latency } \\
(\mathbf{m s})\end{array}$ & $\begin{array}{l}\text { Amplitude } \\
(\mathbf{m V})\end{array}$ & $\begin{array}{l}\text { Conduction } \\
\text { velocity }(\mathbf{m} / \mathbf{s})\end{array}$ \\
\hline Sural R to ankle & $\mathrm{N}<4.5$ & $\mathrm{~N}>6$ & $\mathrm{~N}>43$ \\
\hline Lower leg & $\mathrm{NR}$ & $\mathrm{NR}$ & $\mathrm{NR}$ & \\
\hline Sural L to ankle & $\mathrm{N}<4.5$ & & $\mathrm{~N}>6$ & $\mathrm{~N}>43$ \\
\hline Lower leg & $\mathrm{NR}$ & $\mathrm{NR}$ & $\mathrm{NR}$ & \\
\hline $\begin{array}{l}\text { Median L to } \\
\text { digit II }\end{array}$ & $\mathrm{N}<3.5$ & & $\mathrm{~N}>25$ & $\mathrm{~N}>56$ \\
\hline Wrist & 3.9 & 6.2 & 17.8 & 36.2 \\
\hline Ulnar L to digit V & $\mathrm{N}<3.5$ & & $\mathrm{~N}>10$ & $\mathrm{~N}>55$ \\
\hline Wrist & 4.1 & 5.0 & 13.9 & 34.1 \\
\hline
\end{tabular}

$R=$ right $L=$ left $; m s=$ millisecond $m V=$ millivolt $m / s=$ meters per second; $N=$ normal; $N R=$ not recordable.

of 0-5) revealed upper extremity strength 5 ; lower extremity: hip flexion 4, hip extension 5, knee flexion 5, knee extension 5, ankle dorsiflexion 2, and ankle plantarflexion 3. Sensation was decreased in a symmetric stocking-glove distribution to temperature, pain, and light touch to the lower third of the calves, and decreased vibration to the level of the knees. Reflexes were absent. Additional examination revealed bilateral disc edema and hyperpigmentation of the skin.

On that encounter, suspicion rose for an underlying process associated with malignancy, and a clinical diagnosis of POEMS was suspected. Further laboratory evaluation was notable for thrombocytosis. Immunofixation
Figure 1: Nuclear medicine bone imaging with focal increased radiotracer uptake in the left T12

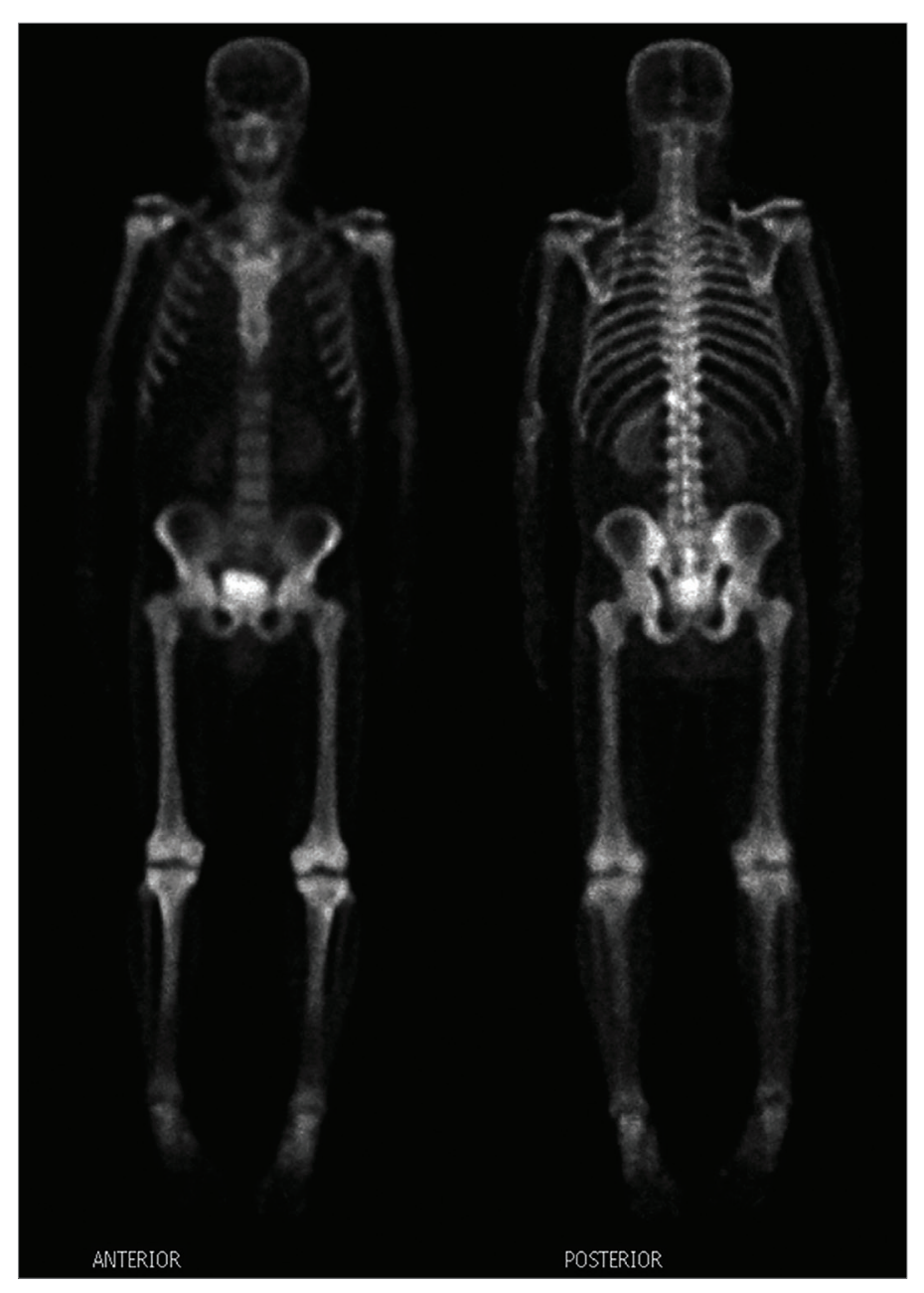

identified an IgA lambda monoclonal protein. Serum-free kappa/lambda light chain ratio was normal. Quantitative immunoglobulin levels revealed an elevated IgA $563 \mathrm{mg} / \mathrm{dL}$ (normal 79-455 mg/dL), with lambda light chain $115.3 \mathrm{mg} / \mathrm{L}$ (normal 5.7-26.3 mg/L) and kappa light chain $73.5 \mathrm{mg} / \mathrm{L}$ (normal 3.3-19.4 mg/L). Serum vascular endothelial growth factor (VEGF) was elevated to $332 \mathrm{pg} / \mathrm{mL}$ (normal $<86 \mathrm{pg} / \mathrm{mL}$ ). Nuclear medicine (NM) bone imaging with technetium 99m-methyl diphosphonate was performed and showed focal increased radiotracer uptake in the left T12 vertebral body (Figure 1), which corresponded to a sclerotic lesion on follow-up positron emission tomography-computed tomography (PET/CT). Multiple additional sclerotic lesions were identified in the manubrium, bilateral ribs, cervical, thoracic, and lumbar spine, posterior right acetabulum, and iliac bones bilaterally. $\mathrm{PET} / \mathrm{CT}$ was also notable for hepatomegaly, as well as multiple prominent cervical, abdominal, pelvic, and inguinal lymph nodes measuring up to $1 \mathrm{~cm}$. This was accompanied by anasarca, including diffuse mesenteric and perinephric edema (Figure 2).

The patient underwent core biopsies of the right acetabulum sclerotic bone lesion which showed a mild increase in CD138+ plasma cells comprising 5\% of cellularity, however without definitive light chain restriction. Bone marrow biopsy showed normocellular bone marrow with moderate erythroid hyperplasia, and 9\% plasma cells with lambda light chain restriction. 
Figure 2: Whole-body positron emission tomographycomputed tomography demonstrates hepatomegaly, diffuse lymphadenopathy, and anasarca

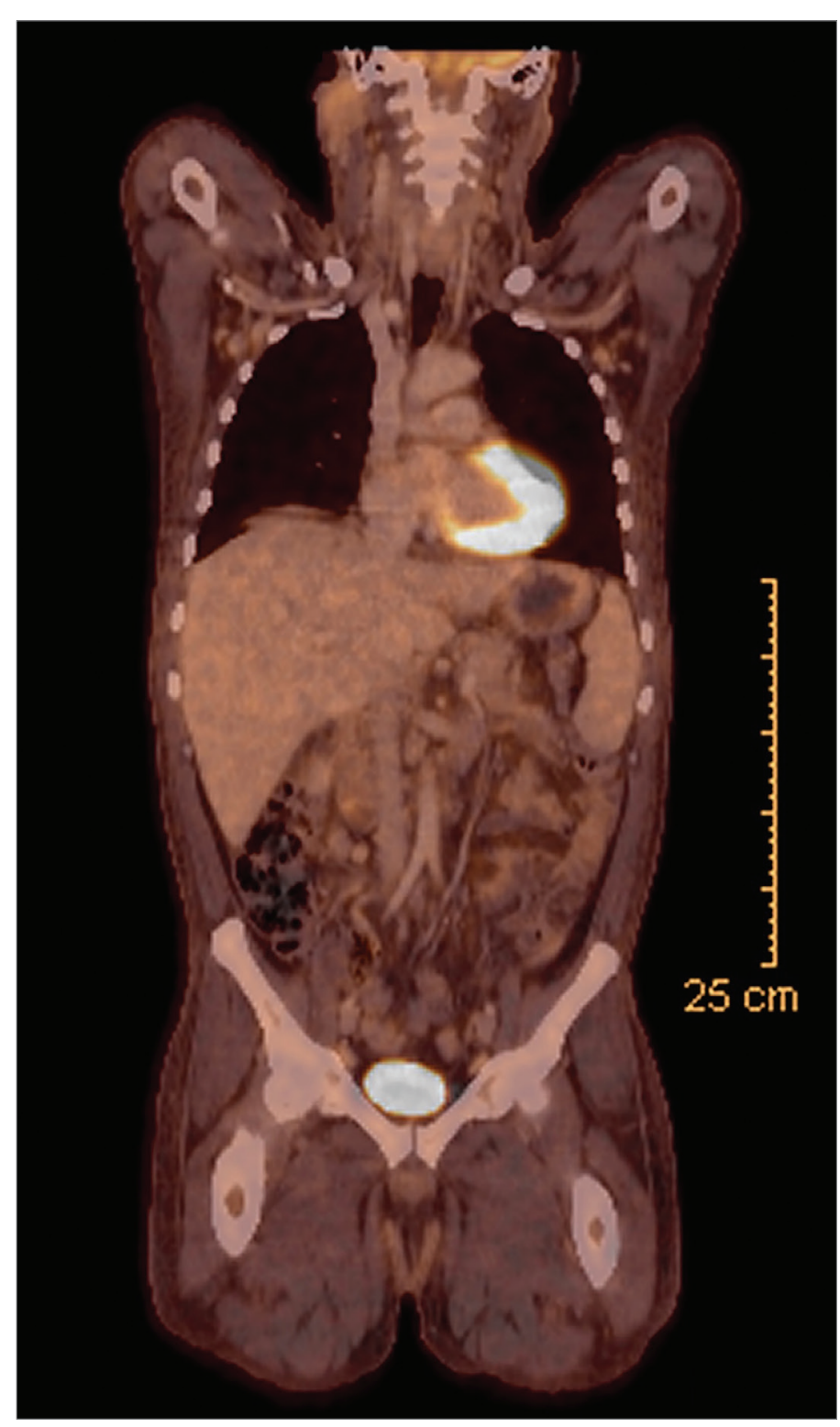

The patient was initiated on lenalidomide-dexamethasone therapy for POEMS. Two weeks after receiving his first dose, the treatment course was complicated by non-ST-elevation myocardial infarction. Lenalidomide was stopped at this point, and the patient was transitioned to CyBorD chemotherapy (cyclophosphamide, bortezomib, dexamethasone) due to concern for the progression of neuropathy.

\section{Discussion}

The constellation of peripheral neuropathy, organomegaly, endocrinopathy, M-proteins, and skin changes was first described as POEMS in 1980 by Bardwick et al in a collection of case studies. ${ }^{1}$ The findings were also separately described in case reports by Crow in $1956,{ }^{2}$ Fukase in $1968,{ }^{3}$ and Takatsuki and Sanada in $1983^{4}$ as peripheral neuritis accompanied by diffuse pigmentation of the skin in the setting of myelomatosis and plasma cell dyscrasia with polyneuropathy and endocrinopathy, lending to its alternate
Table 3: Diagnostic criteria of POEMS syndrome

\begin{tabular}{|c|c|}
\hline $\begin{array}{l}\text { Mandatory criteria } \\
\text { (both required) }\end{array}$ & $\begin{array}{l}\text { - Polyneuropathy (demyelinating) } \\
\text { - Monoclonal plasma cell proliferative disorder } \\
\text { (lambda predominance) }\end{array}$ \\
\hline $\begin{array}{l}\text { Major criteria } \\
\text { (one required) }\end{array}$ & $\begin{array}{l}\text { - } \text { Castleman disease } \\
\text { - Sclerotic bone lesions } \\
\text { - Vascular endothelial growth factor elevation }\end{array}$ \\
\hline $\begin{array}{l}\text { Minor criteria } \\
\text { (one required) }\end{array}$ & $\begin{array}{l}\text { - Organomegaly (splenomegaly, hepatomegaly, or } \\
\text { lymphadenopathy) } \\
\text { - Extravascular volume overload (edema, pleural effusion, } \\
\text { or ascites) } \\
\text { - Endocrinopathy (adrenal, thyroid, pituitary, gonadal, } \\
\text { parathyroid, pancreatic) } \\
\text { - Skin changes (hyperpigmentation, hypertrichosis, } \\
\text { glomeruloid hemangiomata, plethora, acrocyanosis, } \\
\text { flushing, white nails) } \\
\text { - Papilledema } \\
\text { - Thrombocytosis/polycythemia }\end{array}$ \\
\hline
\end{tabular}

names of Crow-Fukase and Takatsuki disease. Despite these case reports and multiple subsequent studies, the pathogenesis of POEMS syndrome is not well understood. ${ }^{5}$

\section{Clinical symptoms}

The diagnosis of POEMS requires a combination of clinical and/or laboratory findings, including two mandatory criteria plus one major and one minor criterion (Table 3): of note, all features of the acronym need not be present. Necessary for the diagnosis are polyneuropathy and monoclonal plasma cell proliferative disorder. Major criteria include the presence of Castleman disease, sclerotic bone lesions, or vascular endothelial growth factor elevation. Minor criteria include organomegaly, extravascular volume overload, endocrinopathy, skin changes (such as hyperpigmentation, hypertrichosis, glomeruloid hemangiomata, plethora, acrocyanosis, flushing, white nails), papilledema, thrombocytosis, and polycythemia. ${ }^{6}$ Nearly all of these features and laboratory findings were observed in the later stages of our patient's disease.

Castleman disease is a rare lymphoproliferative disorder characterized by unicentric or multicentric ${ }^{7}$ angiofollicular lymph node hyperplasia, and is associated with the development of other malignancies ${ }^{8}$ as well as neuropathy. The Castleman disease variant of POEMS has greater severity of demyelinating features and degree of axonal loss when compared with Castleman disease-associated neuropathy that does not fit additional criteria for POEMS. ${ }^{9}$

Worse prognosis is portended by extravascular volume overload, pulmonary hypertension, respiratory symptoms, impaired diffusion capacity of the lungs for carbon dioxide (DLCO), fingernail clubbing, and papilledema. ${ }^{5}$ Papilledema is an early sign and is an independent adverse prognostic factor. The pathophysiology of papilledema in POEMS syndrome is contested, ${ }^{10}$ but it is associated with raised intracranial pressure, elevated CSF protein levels, ${ }^{10}$ and increased vascular permeability secondary to elevated serum VEGF.11

While the constellation of symptoms is more easily recognizable in advanced disease, it is important to have high clinical suspicion for POEMS when patients first present due to concern for underlying malignancy. 
Over $50 \%$ of patients with POEMS syndrome initially complain of neuropathy. In the setting of bilateral sensory and motor involvement, symptoms are often mistaken for CIDP and are only reconsidered when symptoms are refractory to IVIG therapy. In fact, over $60 \%$ of cases are initially misdiagnosed as $\mathrm{CIDP}^{12}$ and the median time to diagnosis is 13-18 months after onset of initial symptoms. ${ }^{13,14}$ Due to this delay in correct diagnosis, appropriate management with radiation, chemotherapy, or bone marrow transplant is often postponed with potential worsening of symptoms and progression of underlying systemic disease.

\section{Diagnostic testing}

Due to the similarities in clinical history and results of diagnostic testing in POEMS syndrome and CIDP, it is often challenging to make the correct diagnosis. Both CIDP and POEMS are chronic progressive neuropathies with motor and sensory components. Electrodiagnostic testing in both entities captures demyelinating polyradiculoneuropathy with axonal features. Although both POEMS and CIDP have significant slowing of conduction velocity, electrophysiological findings in POEMS syndrome show rare conduction block, suggesting that POEMS does not share the same immune-mediated focal demyelination as CIDP. ${ }^{15}$ Demyelination in POEMS predominantly involves the nerve trunk, where the nerve-blood barrier is vulnerable to breakdown in the setting of VEGF.12 In POEMS syndrome, there is more axonal loss than in CIDP, as evidenced by reduced amplitudes of distal motor and sensory potentials. Additionally, greater attenuation of the compound muscle action potentials affects the lower limbs more so than upper limbs in a length-dependent pattern. ${ }^{12,16}$ Wallerian degeneration in axonal polyneuropathy may result in terminally accentuated conduction slowing. ${ }^{15}$ CSF protein level does not differentiate between either condition. A prior study comparing sural nerve biopsies in POEMS and CIDP described that POEMS has higher rates of axonal degeneration, diffuse myelinated nerve fiber loss, uncompacted myelin lamellae, opening of tight junctions between endothelial cells, pinocytic vesicles adjacent to cell membranes, and increased number of small epineurial blood vessels

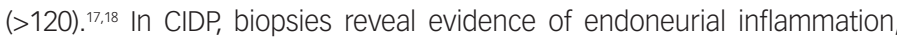
macrophage-associated demyelination, multifocal myelinated fiber loss, and onion bulb formation. ${ }^{12,16,17}$ There is, however, no need, except in rare situations, to perform a nerve biopsy for diagnostic purposes.

A retrospective review comparing POEMS and CIDP patients showed a statistically significant elevation in platelet count with POEMS, suggesting that it is an easy marker when considering the diagnosis of POEMS. ${ }^{19}$ Thrombocytosis has since been added to the list of diagnostic minor criteria, and as a readily available laboratory examination may prove to be a useful screening tool.

\section{Treatment}

The degree of recovery from POEMS neuropathy relies on prompt treatment. ${ }^{20}$ While IVIG and plasmapheresis are proven therapies for CIDP, they are ineffective in POEMS and may delay appropriate management. Treatment for POEMS targets the plasma cell clone and is dependent on the degree of plasma cell infiltration into bone marrow. ${ }^{6}$ Therapies are based on expert recommendation and case series, as there are no existing randomized clinical trials involving POEMS syndrome.

Isolated bony lesions (up to three) without diffuse bone marrow involvement are treated with a standard 40 Gy of radiation. Symptoms improve over 3-36 months, and treatment with radiation is potentially curative. ${ }^{21}$ At times, radiation is accompanied by adjuvant corticosteroid therapy for acute symptomatic management. ${ }^{20}$

If bone marrow is involved, systemic chemotherapy is required. Therapy mirrors that of multiple myeloma and light chain amyloidosis, typically involving high-dose alkylator-based chemotherapy with autologous peripheral blood stem cell transplantation (ASCT), or low-dose chemotherapy with corticosteroids. ASCT has demonstrated a response rate of $100 \%$ in case studies, with recommendations for ASCT with high-dose chemotherapy lenalidomide (15-25 mg orally days 1-21, every 28 days) and weekly dexamethasone. An alternate regimen is cyclophosphamide $\left(750 \mathrm{mg} / \mathrm{m}^{2}\right.$ intravenously every 3 weeks) and $4-5$ days of corticosteroid therapy. ${ }^{20}$ Additional treatments include thalidomide or bortezomib, such as in our patient. Expected neurological response to systemic chemotherapy and ASCT is 6-36 months after completion of therapy. ${ }^{6}$ Of note, lenalidomide-dexamethasone combination carries the risk of thrombosis, while thalidomide and bortezomib are associated with peripheral neuropathy. VEGF levels are monitored as a surrogate of therapeutic response. However, anti-VEGF therapies such as bevacizumab that lead to undetectable VEGF levels disappointingly have not translated to consistently demonstrable clinical benefit. ${ }^{20}$

\section{Conclusion}

As patients with POEMS syndrome have an increased risk of life-threatening thrombogenic events including myocardial infarction, ischemic stroke, splenic infarction, and venous thrombosis, any misdiagnosis as CIDP or delay in appropriate diagnosis may result in disease progression and additional complications. High clinical suspicion and recognition of the electrodiagnostic findings early in the disease course when a patient presents only with neuropathy are key in the proper diagnosis and management of POEMS. Cases of 'CIDP' or monoclonal gammopathy should be studied for the possibility of this complex syndrome.
1. Bardwick PA, Zvaifler JN, Gill GN, et al. Plasma cell dyscrasia with polyneuropathy, organomegaly, endocrinopathy, M protein, and skin changes: the POEMS syndrome. Report on two cases and a review of the literature. Medicine. 1980;59:311-22.

2. Crow RS. Peripheral neuritis in myelomatosis. BMJ. 1956;2:792-4 802-4.

3. Nakanishi T, Sobue I, Toyokura Y, et al. The Crow-Fukase syndrome: a study of 102 cases in Japan. Neurology. 1984;34:712-20.

4. Takatsuki K, Sanada I. Plasma cell dyscrasia with polyneuropathy and endocrine disorder. clinical and laboratory features of 109 reported cases. Jap J Clin Oncol. 1983;13:543-55.

5. Dispenzieri A. POEMS syndrome: 2017 update on diagnosis, risk stratification, and management. Am J Hematol. 2017;92:814-29. 6. Dispenzieri A. POEMS syndrome: update on diagnosis, riskstratification, and management. Am J Hematol. 2015;90:951-62.

. Soumerai JD, Sohani AR, Abramson IS. Diagnosis and management of Castleman disease. Cancer Control. 2014; 21:266-78.

8. Mauermann, M. The peripheral neuropathies of POEMS syndrome and Castleman disease. Hematol Oncol Clin North Am
2018;32:153-63.

Naddaf E, Dispernzieri A, Mandrekar J, et al. Clinical spectrum of Castleman disease-associated neuropathy. Neurology. 2016:87:2457-62.

10. Cui $R$, Yu S, Huang $X$, et al. Papilloedema is an independent prognostic factor for POEMS syndrome. J Neurol. 2014;261:60-5.

11. Chong DY, Corner GM, Trobe JD. Optic disc edema, cystoid macular edema, and elevated vascular endothelial growth factor in a patient with POEMS syndrome. J Neuro-Ophthalmol. 2007;27:180-3.

12. Nasu S, Misawa S, Sekiguchi Y, et al. Different neurological and physiological profiles in POEMS syndrome and chronic inflammatory demyelinating polyneuropathy. J Neurol Neurosurg Psych. 2012;83:476-9.

13. Dispenzieri A, Kyle RA, Lacy MQ, et al. POEMS syndrome: definitions and long-term outcome. Blood. 2003;101:2496-506.

14. Li J, Zhou DB, Huang Z, et al. Clinical characteristics and longterm outcome of patients with POEMS syndrome in China. Ann Hematol. 2001:90:819-26.
15. Min JH, Hong YH, Lee KW. Electrophysiological features of patients with POEMS syndrome. Clin Neurophysiol. 2005;116:965-8.

16. Mauermann ML, Sorenson EJ, Dispenzieri A, et al. Uniform demyelination and more severe axonal loss distinguish POEMS syndrome from CIDP. J Neurol Neurosurg Psych. 2012;83:480-6.

17. Piccione EA, Engelstad J, Dyck PJ, et al. Nerve pathologic features differentiate POEMS syndrome from CIDP. Acta Neuropatholog Comm. 2016;4:116.

18. Vital C, Bouillot S, Vital A. Significance of uncompacted myelin lamellae in POEMS syndrome. Muscle Nerve. 2003;27:253-4.

19. Naddaf E, Dispenzieri A, Mandrekar J, et al. Thrombocytosis distinguishes POEMS syndrome from chronic inflammatory demyelinating polyneuropathy. Muscle Nerve. 2015;52:658-9.

20. Dispenzieri A. How I treat POEMS syndrome. Blood 2012;119:5650-8.

21. Humeniuk MS, Gertz MA, Lacy MQ, et al. Outcomes of patients with POEMS syndrome treated initially with radiation. Blood. 2013;122:68-73. 